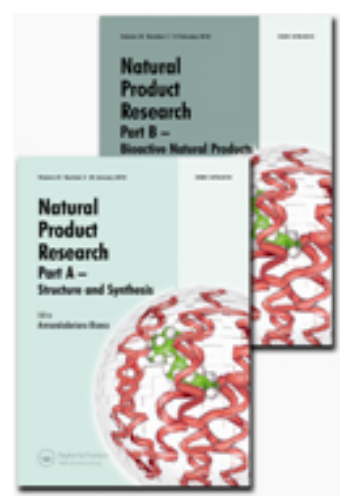

\title{
High-Resolution Magic Angle Spinning Nuclear Magnetic Resonance (HR-MAS-NMR) as quick and direct insight of almonds
}

\begin{tabular}{|c|c|}
\hline Journal: & Natural Product Research \\
\hline Manuscript ID & Draft \\
\hline Manuscript Type: & Research Article \\
\hline $\begin{array}{r}\text { Date Submitted by the } \\
\text { Author: }\end{array}$ & $\mathrm{n} / \mathrm{a}$ \\
\hline Complete List of Authors: & $\begin{array}{l}\text { Salvo, Andrea; University of Messina, Dipartimento di Scienze } \\
\text { dell'Ambiente, della Sicurezza, del Territorio, degli Alimenti e della Salute } \\
\text { (S.A.S.T.A.S.) } \\
\text { Rotondo, Archimede; University of Messina, Department of Biomedical } \\
\text { and Dental Sciences and Morphofunctional Imaging } \\
\text { Mangano, Valentina; University of Messina, Department of Food and } \\
\text { Environmental Sciences ( S.A.S.T.A.S) } \\
\text { Grimaldi, Manuela; University of Salerno, Fisciano (SA), Italy., } \\
\text { Department of Pharmacy DIFARMA } \\
\text { Stillitano, Ilaria; University of Salerno, Fisciano (SA), Italy., Department } \\
\text { of Pharmacy DIFARMA } \\
\text { D'Ursi, Anna Maria; University of Salerno, Fisciano (SA), Italy., } \\
\text { Department of Pharmacy DIFARMA } \\
\text { Dugo, Giacomo; University of Messina, Food and Environmental Science } \\
\text { "Prof. G. Stagno d'Alcontres" } \\
\text { Rastrelli , Luca; University of Salerno, Fisciano (SA), Italy., Department } \\
\text { of Pharmacy DIFARMA }\end{array}$ \\
\hline Keywords: & Food composition, HR-MAS-NMR, almonds, PCA, quantification \\
\hline
\end{tabular}

\section{SCHOLARONE ${ }^{m}$ Manuscripts}




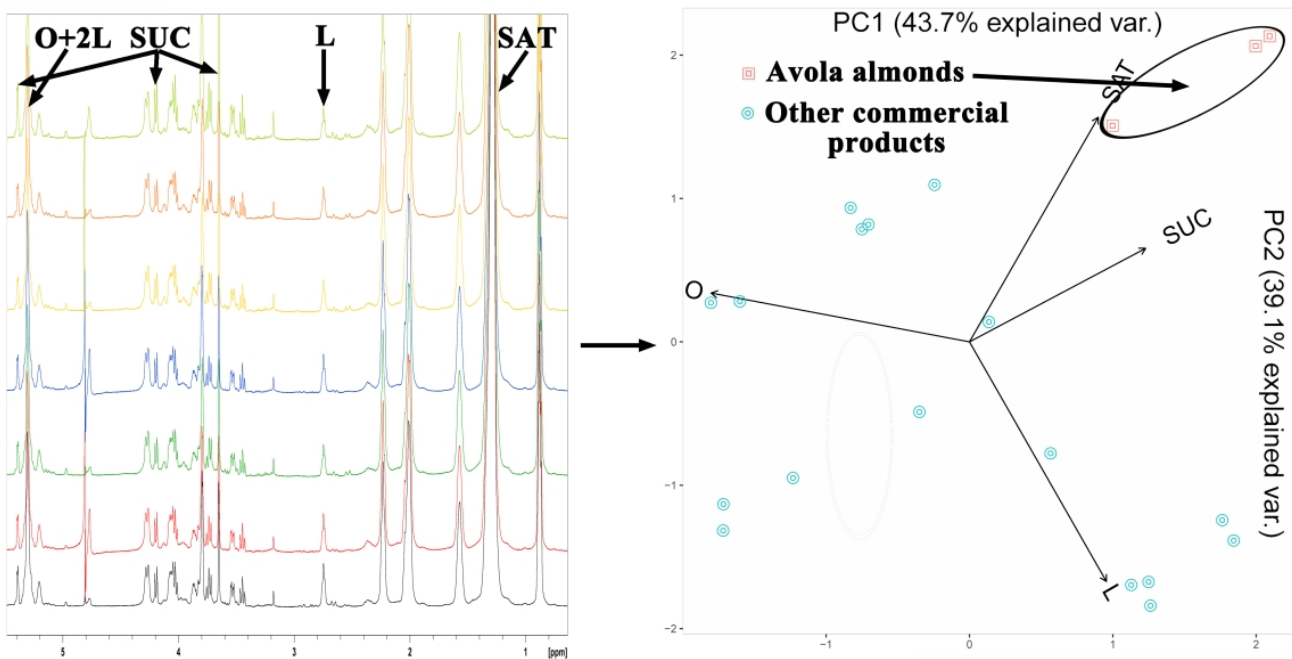

$371 \times 188 \mathrm{~mm}(300 \times 300$ DPI $)$ 


\title{
High-Resolution Magic Angle Spinning Nuclear Magnetic Resonance (HR-MAS-NMR) as quick and direct insight of almonds
}

\author{
Andrea Salvo ${ }^{1,2}$, Archimede Rotondo ${ }^{1 *}$, Valentina Mangano ${ }^{1}$, Manuela Grimaldi ${ }^{3,4}$, Ilaria \\ Stillitano $^{3}$, Anna Maria D’Ursi ${ }^{3}$, Giacomo Dugo ${ }^{1,2}$, Luca Rastrelli ${ }^{3}$. \\ ${ }^{1}$ Department of Biomedical and Dental Sciences and Morphofunctional Imaging, University of \\ Messina, Polo Universitario Annunziata, 98168 Messina \\ ${ }^{2}$ Science4Life, Spin Off Company, University of Messina, Viale Leonardo Sciascia Coop Fede Pal. \\ B - 98168 Messina. \\ ${ }^{3}$ Department of Pharmacy DIFARMA, University of Salerno, Fisciano (SA), Italy. \\ ${ }^{4}$ Institute of Polymers, Composites and Biomaterials, National Research Council of Italy, V.le J.F. \\ Kennedy 54 - Pad. 20 Mostra d'Oltremare, 80125 Naples, Italy.
}

\begin{abstract}
Andrea Salvo, asalvo@unime.it
Archimede Rotondo, arotondo@unime.it

Valentina Mangano, vmangano@unime.it

Manuela Grimaldi, magrimaldi@unisa.it

Ilaria Stillitano, istillitano@unisa.it

Anna Maria D’Ursi, dursi@unisa.it

Giacomo Dugo,dugog@unime.it

Luca Rastrelli, rastrelli@unisa.it
\end{abstract}
*Address correspondence to Archimede Rotondo Dep. Biomorf., University of Messina, Italy; Phone: +390906766890;
E-mail: arotondo@unime.it


Abstract

Almonds are the tasty seeds of Prunus dulcis plants globally appreciated for the pleasant palatability and remarkable nutritional value, therefore it is very spread as snack and as basic ingredient of the confectionery products. The HR-MAS-NMR is a simple spectroscopy able to directly and quickly explore the chemical composition of powdered seed samples dispersed in $\mathrm{D}_{2} \mathrm{O}$. ${ }^{1} \mathrm{H}$ spectra witness the remarkable presence of triglyceride fatty esters together with sucrose; other minor water soluble metabolites are also detectable. This very rough approach is effectively providing chemical profiles featuring almond samples. In this analysis we were able to statistically distinguish the "Avola" almonds from other marketed products submitted to the same analysis. This is just a first investigation based on the main compounds but it might pave the way toward the quantitative evaluation of many other compounds in the almond therefore implementing the HRMAS-NMR knowledge of these precious seeds.

Keywords: Food composition, HR-MAS-NMR, almonds, PCA, Quantification.

\section{Introduction}

Almonds (Prunus Dulcis) belong to the Rosaceae family and are globally appreciated for their sensory and health features; as it is an important element of the Mediterranean diet and main ingredient of many confectionery industries, almond trees are the most grown on a global basis (Siriwardhana Wijeratne et al. 2006; Chen et al. 2005). Many Mediterranean regions are characterized by these plants bearing a considerable commercial value (Martins et al. 2003; Cicero et al. 2015; Albergamo et al. 2017; Costa et al. 2018). The edible fruit presents three distinct parts: 1) the inner kernel or meat (sold with or without the brown skin), 2) the middle shell portion, and an outer green shell cover or hull. All these parts are deeply studied for the chemical composition being the meat the most important consumable food whereas the outer parts can be recycled as "useful waste" (Esfahlan et al. 2010). Almonds are a rich source of essential fatty acids, carbohydrate and protein and is a highly nutritional source of vitamins, minerals (Gallier et al. 2012) and antioxidant species claimed to slow aging processes (Franklin et al. 2017). This accounts for the careful chemical analyses of almonds aimed to elucidate the beneficial effects of derived products upon the human health (Zeeshan 2010; Geng et al. 2016).

Almonds, when incorporated in the diet, have been reported to increase the "good cholesterol" (high density lipo-proteins, HDL) in spite of the "bad cholesterol" (low density lipo-proteins, LDL) levels 
in humans (Ahmad 2010; Hyson et al. 2002). Extracts of whole almond seed, brown skin, shell, and green shell cover (hull) bear potent free radical-scavenging capacities (Sfahlan et al. 2009; Moure et al. 2007; Siriwardhana Wijeratne et al. 2006); these activities are related to the presence of flavonoids and other phenolic compounds recalling the need of the molecular composition approach (Shahidi et al. 2009). In the field of the chemical studies, nuclear magnetic resonance (NMR) is an irreplaceable tool for the chemical characterization (Rotondo et al. 2012; Rotondo et al. 2014a), elucidation of structures and molecular dynamic behavior (Rotondo et al. 2014b; Rotondo et al. 2015), allowing also characterization of complex mixtures (Salvo et al. 2017). NMR spectroscopy is very efficient for the simultaneous detection and identification of several metabolites (Rotondo et al. 2011, Rotondo et al. 2017) indeed almond oils were deeply analyzed by high resolution NMR (Popescu et al. 2015) as well as the almonds water-soluble extracts (Tanaka et al. 2013).

HR-MAS-NMR spectroscopy opened-up the chance to analyse the solid and semisolid matter (Corsaro et al. 2016) which, in the case of the Prunus Dulcis turned out to allow direct chemical changes undergone by almonds upon irradiation processes (Ribó et al. 2004). The aim of this work is to characterize the chemical composition of Prunus Dulcis by semi-solid NMR analysis to provide the simultaneous relative quantification of very different chemical species as fats and carbohydrates. To our knowledge this is the first HR-MAS study aimed to draw chemical profiles related to different marketed edible Prunus Dulcis seeds, paving the way to deeper investigations on this interesting matrix.

\section{Results and discussion}

The most important results are obtained by the integration of the ${ }^{1} \mathrm{H}$ pre-saturated experiments and the assignment provided by the used 2D-techniques and by the other literature findings (Figure 1). The different almond samples display a similar qualitative spectral profile (Figure 1S supplemental text). The main relative quantitative values (Table 1) are within the ranges expected by the other literature data (Esfhalan 2010; Ahmad 2012; Barreira et al. 2012).

The principal purpose of the paper is to use the direct HR-MAS-NMR analysis for the first simultaneous relative quantification of the main fatty esters (already observed by Ribó et al. 2004) together with the sucrose. Moreover, with this careful study, it is paved the way to quantify other less represented water-soluble metabolites (such as aspartic acid, proline, phosphocholine derivates and other sugars) respect to the fatty acylglycerols which are certainly the most represented species of the whole almond seeds (Figure 1 and Table 2S). Because of the limited number of samples, for some statistical consideration, we have selected just the saturated (palmitates and stearates, SAT), 


\section{Experimental}

Almonds taken from 24 samples of seven different types and grouped in three different belongings (Table 1S) were milled in a stone mortar. Small aliquots of $15-28 \mathrm{mg}$ were homogenized with 100 $\mu \mathrm{L}$ of $\mathrm{D}_{2} \mathrm{O}$, the spectra were acquired at a temperature of $300 \mathrm{~K}$, the mixture was put inside the 4$\mathrm{mm} \mathrm{ZrO}_{2}$ rotor (detection volume $12 \mu \mathrm{L}$ ), and with a hemispherical Teflon insert for HR-MAS NMR analysis. All NMR spectroscopic studies were performed with a Bruker DMX 500 NMR spectrometer equipped with an HR-MAS accessory and a ${ }^{1} \mathrm{H} /{ }^{13} \mathrm{C}$ gradient probe and controlled by Topspin 3.2 software package for set-up, acquisition and processing procedures. The sample spinning rate was kept $4 \mathrm{kHz}$ with a magic angle of $56^{\circ}$.

In order to obtain information we have optimized the $90^{\circ}$ pulses for the ${ }^{1} \mathrm{H}$ nucleus. We have run: 1) ${ }^{1} \mathrm{H}-1 \mathrm{D}$ experiments with $\mathrm{f} 1$ pre-saturation (zgpr) were acquired with time domain size of $32 \mathrm{k}$, sweep width of $12 \mathrm{ppm}$, acquisition time of $2.7 \mathrm{sec}$, dwell time of $83.2 \mu \mathrm{sec}$, relaxation delay of 2.0 sec, dummy scan of 2 and number of scan 16;2) the ${ }^{13} \mathrm{C}-\mathrm{NMR}$ spectra were acquired with time domain size of $64 \mathrm{k}$, sweep width of $20 \mathrm{ppm}$, acquisition time of $3.2 \mathrm{sec}$, dwell time of $50.0 \mu \mathrm{sec}$, pre-scan-delay of $6.5 \mu \mathrm{sec}$, relaxation delay $2.0 \mathrm{sec}$, dummy scan of 2 and number of scan $800 ; 3$ ) in order to confirm and elucidate the chemical nature of the analyzed matter ${ }^{1} \mathrm{H}-2 \mathrm{D}-\mathrm{COSY}$ 
experiment were acquired with size FID of 128, time domain size of $3 \mathrm{k}$, sweep width of $12 \mathrm{ppm}$, acquisition time of $0.3 \mathrm{sec}$, dwell time of $83.2 \mu \mathrm{sec}$, pre-scan-delay of $6.5 \mu \mathrm{sec}$, relaxation delay of $1.3 \mathrm{sec}$, dummy scan of 2 and number of scan 16.

As reference signal for the frequency calibration we have adopted the terminal methyl group of the fatty ester chains $(\delta=0.88 \mathrm{ppm})$ whereas as quantitative relative reference we have chosen the $\alpha$ $\mathrm{CH}_{2}$ group of the fatty esters resonating at $\delta=2.25 \mathrm{ppm}$. On these bases we could readily extract the relative concentration of fatty esters and of the main sugar sucrose. Other metabolites are tentatively quantified according to well known assigned integrations. The overall discussion is based just on the four main metabolites. All the quantification measurements of the used four metabolites were verified for their uncertainty by accomplishment of many different experiments over three homologous samples.

To quickly identify the differences among the almond samples we have run the simple statistical analysis by principal components (PCA); as we had just 24 samples we have reduced the number of quantitative variables to the main four species. By the use of $\mathrm{R}$ software, the first two dimensions were used to display the sample mutual relationship (supplemental text, Figure $2 \mathrm{~S}$ ).

\section{Conclusions}

HR-MAS-NMR analysis is a straightforward tool to investigate almonds and almond seeds without chemical modification or dissolution opening up the way for a direct relative quantification of species of different nature such as the hydrophobic triacylglycerol esters and the hydrophilic carbohydrates and amino-acids. This preliminary study exploits the relative presence of the three main fatty esters and sucrose in order to discriminate several marketed samples from "Avola" almonds grown and collected in Sicily, provided that all the analysed samples showed a chemical profile compatible with good quality products. "Avola" almonds showed definitely higher relative concentration of sucrose respect to the fatty esters. This study paves the way toward the quick elucidation of the almond chemical nature with also a straightforward strategy for geographical characterization and traceability.

\section{References}

Ahmad Z. 2010. The uses and properties of almond oil. Complement Ther Clin. 16:10-12. 
Albergamo A, Rotondo A, Salvo A, Pellizzeri V, Bua DG, Maggio A, Cicero N, Dugo G. 2017. Metabolite and mineral profiling of "Violetto di Niscemi" and "Spinoso di Menfi" globe artichokes by1H-NMR and ICP-MS. Nat Prod Res. 31(9):990-999.

Barreira JCM, Casal S, Ferreira ICFR, Peres AM, Pereira JA, Oliveira MBPP. 2012. Supervised Chemical Pattern Recognition in Almond (Prunus dulcis) Portuguese PDO Cultivars: PCA- and LDA-Based Triennial Study. J Agric Food Chem. 60:9697-9704.

Chen CY, Milbury PE, Lapsley K, Blumberg JB. 2005. Flavonoids from almond skins are bioavailable and act synergistically with vitamins $\mathrm{C}$ and $\mathrm{E}$ to enhance hamster and human LDL resistance to oxidation. J Nutr. 135:1366-1373.

Cicero N, Corsaro C, Salvo A, Vasi S, Giofrè SV, Ferrantelli V, Di Stefano V, Mallamace D, Dugo G. 2015. The metabolic profile of lemon juice by proton HR-MAS NMR: The case of the PGI Interdonato Lemon of Messina. Nat Prod Res. 29 (20):1894-1902.

Corsaro C, Cicero N, Mallamace D, Vasi S, Naccari C, Salvo A, Giofrè SV, Dugo G. 2016. HRMAS and NMR towards Foodomics. Food Research International, 89: 1085-1094.

Costa R, Salvo A, Rotondo A, Bartolomeo G, Pellizzeri V, Saija E, Arrigo S, Interdonato M, Trozzi A, Dugo G. 2018. Combination of separation and spectroscopic analytical techniques: application to compositional analysis of a minor citrus species. Nat Prod Res. 32 (21): 2596-2602.

Esfahlan AJ, Jamei R, Esfahlan RJ. 2010. The importance of almond (Prunus amygdalus L.) and its by-products. Food Chem. 120:349-360.

Franklin LM, Chapman DM, King ES, Mau M, Huang G, Mitchell AE. 2017. Chemical and Sensory Characterization of Oxidative Changes in Roasted Almonds Undergoing Accelerated Shelf-life. J Agric Food Chem. 65:2549-2563.

Gallier S, Gordon KC, Singh H. 2012. Chemical and structural characterisation of almond oil bodies and bovine milk fat globules. Food Chem. 132:1996-2006. 
Geng H, Yu X, Lu A, Cao H, Zhou B, Zhou L, Zhao Z. 2016. Extraction, Chemical Composition, and Antifungal Activity of Essential Oil of Bitter Almond. Int J Mol Sci. 17:1421.

Hyson DA, Schneeman BO, Davis PA. 2002. Almonds and Almond Oil Have Similar Effects on Plasma Lipids and LDL Oxidation in Healthy Men and Women. J Nutr. 132: 703-707.

Martins M, Tenreiro R, Oliveira MM. 2003. Genetic relatedness of Portuguese almond cultivars assessed by RAPD and ISSR markers. Plant Cell Rep. 22:71-78.

Moure A, Pazos M, Medina I, Domínguez H, Parajó JC. 2007. Antioxidant activity of extracts produced by solvent extraction of almond shells acid hydrolysates. Food Chem. 101:193-201.

Popescu R, Costinel D, Dinca OR, Marinescu A, Stefanescu I, Ionete RE. 2015. Discrimination of vegetable oils using NMR spectroscopy and chemometrics. Food Control. 48: 84-90.

Ribó JM, Crusats J, El-Hachemi Z, Feliz M, Sanchez-Bel P, Romojaro F. 2004. High-Resolution NMR of Irradiated Almonds. J Am Oil Chem.' Soc. 81(11): 1029-1033.

Rotondo A., Barresi S., Cusumano M., Rotondo E. 2012. Structural and dynamic NMR characterization of $\left[\mathrm{Pd}(\text { bipy })(\mathrm{R} \text {-thiourea })_{2}\right]^{2+}$ and $\left[\mathrm{Pd}(\mathrm{phen})(\mathrm{R} \text {-thiourea })_{2}\right]^{2+}$ cations. Polyhedron 45(1):23-29

Rotondo A., Barresi S., Cusumano M., Rotondo E., Donato P., Mondello L. 2014a. NMR characterisation and dynamic behaviour of $\left[\mathrm{Pt}(\right.$ bipy $\left.)(\mathrm{R}-\mathrm{Thiourea})_{2}\right] \mathrm{Cl}_{2}$ and $[\mathrm{Pt}(\mathrm{phen})(\mathrm{R}-$ Thiourea $\left.)_{2}\right] \mathrm{Cl}_{2}$ complexes. Inorganica Chim Acta. 410:1-10.

Rotondo A., Ettari R., Zappalà M., De Micheli C., Rotondo E. 2014b. NMR characterization and conformational analysis of a potent papain-family cathepsin L-like cysteine protease inhibitor with different behaviour in polar and apolar media J Mol Struct. 1076:337-343.

Rotondo A., Ettari R., Grasso S., Zappalà M. 2015. NMR conformational analysis in solution of a potent class of cysteine proteases inhibitors Struct. Chem. 26(4): 943-950 
Rotondo A, Salvo A, Gallo V, Rastelli L, Dugo G. 2017. Quick unreferenced NMR quantification of Squalene in vegetable oils. Eur J Lipid Sci. Technol. 119(11). Article number 1700151.

Rotondo A, Salvo A, Giuffrida D, Dugo G, Rotondo E. 2011. NMR analysis of aldehydes in sicilian extra-virgin olive oils by DPFGSE techniques. Atti Accad Pelorit Pericol., Cl. Sci. Fis. Mat. Nat. 89(1). DOI: $10.1478 / \mathrm{C} 1 \mathrm{~A} 8901002$

Salvo A, Rotondo A, La Torre GL, Cicero N, Dugo G. 2017. Determination of 1,2/1,3-diglycerides in Sicilian extra-virgin olive oils by ${ }^{1} \mathrm{H}-\mathrm{NMR}$ over a one-year storage period. Nat Prod Res. 31(7):822-828.

Sfahlan AJ, Mahmoodzadeh A, Hasanzadeh A, Heidari R, Jamei R. 2009. Antioxidants and antiradicals in almond hull and shell (Amygdalus communis L.) as a function of genotype. Food Chem. 115:529-533.

Shahidi F, Zhong Y, Wijeratne SSK, Ho CT. 2009. Tree nuts: nutraceuticals, phytochemicals, and health effects. Boca Raton: Taylor \& Francis Group. Chapter 8 Almond and almond products: Nutraceutical components and health effects p. 127-141.

Siriwardhana Wijeratne SSK, Amarowicz R, Shahidi F. 2006. Antioxidant Activity of Almonds and Their By-products in Food Model Systems. Journal of the American Oil Chemists' Society. 83:223230.

Tanaka R, Nitta A, Nagatsu A. 2013. Application of a quantitative ${ }^{1} \mathrm{H}-\mathrm{NMR}$ method for the determination of amygdalin in Persicae semen, Armeniacae semen, and Mume fructus. Journal of Natural Medicines. 68(1):225-230.

Zeeshan, A. 2010. The uses and properties of almond oil. Complementary Therapies in Clinical Practice. 16:10-12. 


\section{Captions}

Table 1. Main chemical composition in relative molecular $\%$ respect to the total fatty esters for the 24 almond seeds samples.

Figure 1. HR-MAS ${ }^{1} \mathrm{H}-\mathrm{NMR}$ experiment for an "Avola" type almond sample; proton assignment is also graphically labeled with the following labels: sucrose (SUC), linoleate esters (L), oleate esters (O), phospho-choline derivates (PCHO), asparagine (ASN), malate (MAL), proline (PRO). 
Table 1. Main chemical composition in relative molecular \% respect to the total fatty esters for the 24 almond seeds samples.

\begin{tabular}{|c|c|c|c|c|}
\hline Sample & $\begin{array}{c}\text { Saturated fatty } \\
\text { esters (SAT) } \%\end{array}$ & $\begin{array}{c}\text { Oleate fatty } \\
\text { esters (0) } \%\end{array}$ & $\begin{array}{c}\text { Linoleate fatty } \\
\text { esters (L) } \%\end{array}$ & $\begin{array}{c}\text { Sucrose (SUC) } \\
\text { relative } \%\end{array}$ \\
\hline S_1_1 & $11.3 \pm 0.6$ & $61.5 \pm 0.4$ & $27.2 \pm 0.6$ & $79.8 \pm 0.8$ \\
\hline S_1_2 & $12.9 \pm 0.6$ & $59.3 \pm 0.4$ & $27.9 \pm 0.8$ & $77.9 \pm 0.8$ \\
\hline S_1_3 & $12.4 \pm 0.6$ & $60.1 \pm 0.4$ & $27.5 \pm 0.6$ & $76.2 \pm 0.8$ \\
\hline S_1_4 & $11.8 \pm 0.6$ & $60.9 \pm 0.4$ & $27.3 \pm 0.6$ & $78.3 \pm 0.8$ \\
\hline S_1_5 & $11.3 \pm 0.6$ & $61.5 \pm 0.6$ & $27.2 \pm 0.6$ & $79.8 \pm 0.7$ \\
\hline S_2_1 & $9.2 \pm 0.6$ & $68.9 \pm 0.4$ & $21.9 \pm 0.6$ & $70.7 \pm 0.6$ \\
\hline S_2_2 & $9.9 \pm 0.6$ & $67.7 \pm 0.6$ & $22.4 \pm 0.6$ & $73.5 \pm 0.8$ \\
\hline S_2_3 & $10.1 \pm 0.6$ & $67.5 \pm 0.4$ & $22.5 \pm 0.6$ & $72.8 \pm 0.8$ \\
\hline S_3_1 & $9.3 \pm 0.6$ & $69.7 \pm 0.6$ & $21.0 \pm 0.6$ & $77.1 \pm 0.8$ \\
\hline S_3_2 & $9.1 \pm 0.6$ & $69.5 \pm 0.4$ & $21.4 \pm 0.6$ & $68.7 \pm 0.8$ \\
\hline S_3_3 & $9.1 \pm 0.6$ & $68.9 \pm 0.4$ & $22.0 \pm 0.6$ & $72.5 \pm 0.8$ \\
\hline S_4_1 & $12.5 \pm 0.6$ & $69.3 \pm 0.4$ & $18.2 \pm 0.6$ & $70.1 \pm 0.8$ \\
\hline S_4_2 & $11.8 \pm 0.6$ & $70.2 \pm 0.5$ & $17.9 \pm 0.7$ & $71.8 \pm 0.8$ \\
\hline S_4_3 & $10.8 \pm 0.6$ & $71.6 \pm 0.4$ & $17.6 \pm 0.7$ & $72.9 \pm 0.8$ \\
\hline S_5_1 & $12.6 \pm 0.6$ & $69.1 \pm 0.5$ & $18.3 \pm 0.7$ & $70.6 \pm 0.8$ \\
\hline S_5_2 & $10.5 \pm 0.6$ & $72.1 \pm 0.4$ & $17.4 \pm 0.7$ & $73.9 \pm 0.8$ \\
\hline S_5_3 & $11.9 \pm 0.6$ & $69.9 \pm 0.6$ & $18.2 \pm 0.7$ & $70.8 \pm 0.8$ \\
\hline S_6_1 & $12.0 \pm 0.6$ & $69.9 \pm 0.4$ & $18.0 \pm 0.7$ & $71.4 \pm 0.8$ \\
\hline S_6_2 & $14.1 \pm 0.6$ & $66.6 \pm 0.4$ & $19.3 \pm 0.7$ & $70.3 \pm 0.8$ \\
\hline S_6_3 & $11.6 \pm 0.6$ & $67.5 \pm 0.4$ & $20.9 \pm 0.7$ & $78.2 \pm 0.8$ \\
\hline S_7_1 & $12.7 \pm 0.6$ & $69.6 \pm 0.4$ & $17.7 \pm 0.7$ & $106.8 \pm 0.6$ \\
\hline S_7_2 & $10.2 \pm 0.6$ & $73.3 \pm 0.4$ & $16.4 \pm 0.7$ & $113.7 \pm 0.5$ \\
\hline S_7_3 & $11.0 \pm 0.6$ & $72.2 \pm 0.4$ & $16.8 \pm 0.7$ & $111.0 \pm 0.6$ \\
\hline
\end{tabular}




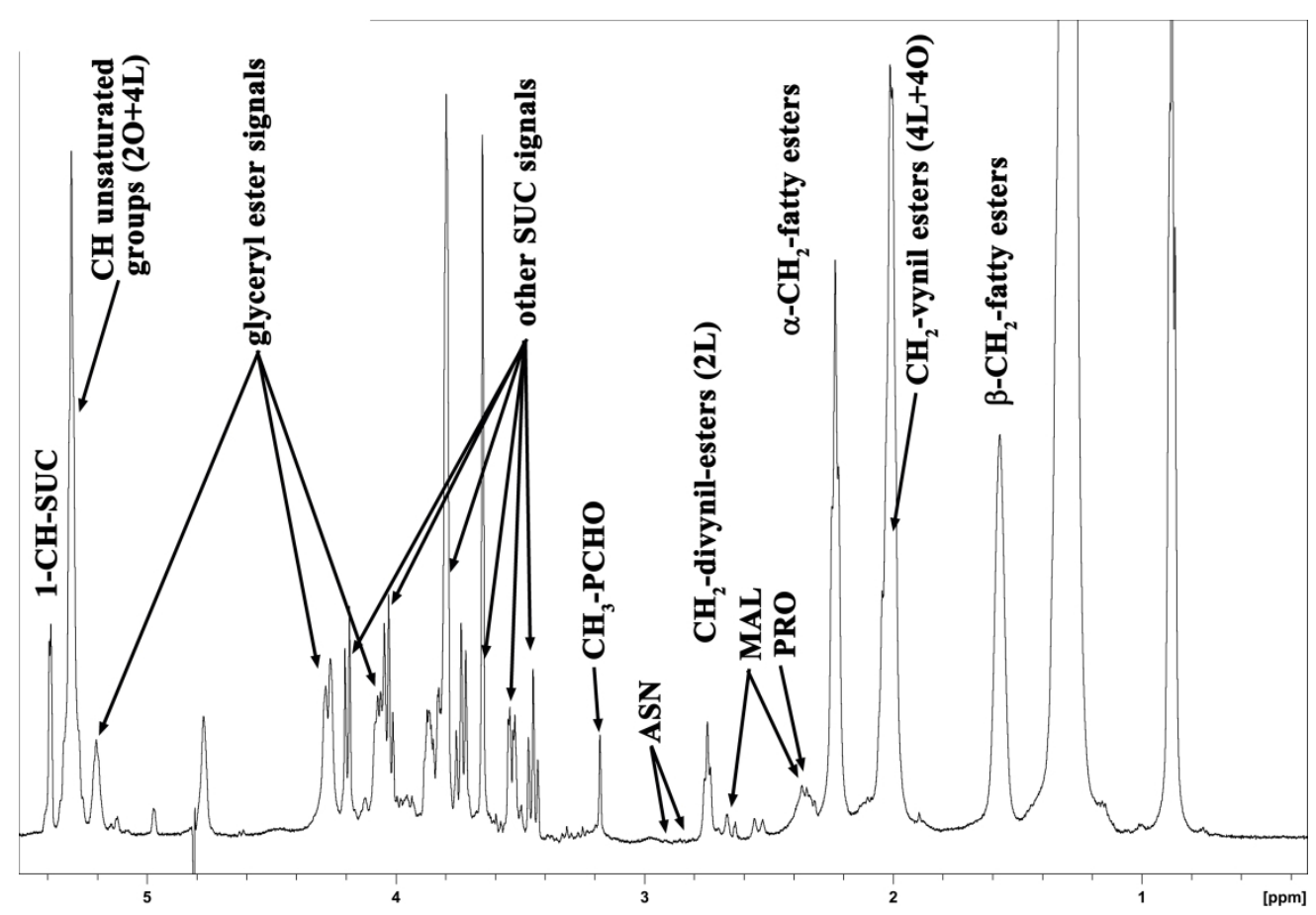

Figure 1. HR-MAS $1 \mathrm{H}-\mathrm{NMR}$ experiment for an "Avola" type almond sample; proton assignment is also graphically labeled with the following labels: sucrose (SUC), linoleate esters (L), oleate esters (O), phosphocholine derivates $(\mathrm{PCHO})$, asparagine $(\mathrm{ASN})$, malate $(\mathrm{MAL})$, proline $(\mathrm{PRO})$.

$159 \times 110 \mathrm{~mm}(600 \times 600 \mathrm{DPI})$ 


\title{
High-Resolution Magic Angle Spinning Nuclear Magnetic Resonance (HR-MAS-NMR) as quick and direct insight of almonds
}

\author{
Andrea Salvo ${ }^{1,2}$, Archimede Rotondo ${ }^{1 *}$, Valentina Mangano ${ }^{1}$, Manuela Grimaldi ${ }^{3,4}$, Ilaria \\ Stillitano $^{3}$, Anna Maria D’Ursi ${ }^{3}$, Giacomo Dugo ${ }^{1,2}$, Luca Rastrelli ${ }^{3}$. \\ ${ }^{1}$ Department of Biomedical and Dental Sciences and Morphofunctional Imaging, University of \\ Messina, Polo Universitario Annunziata, 98168 Messina \\ ${ }^{2}$ Science4Life, Spin Off Company, University of Messina, Viale Leonardo Sciascia Coop Fede Pal. \\ B - 98168 Messina. \\ ${ }^{3}$ Department of Pharmacy DIF ARMA, University of Salerno, Fisciano (SA), Italy. \\ ${ }^{4}$ Institute of Polymers, Composites and Biomaterials, National Research Council of Italy, V.le J.F. \\ Kennedy 54 - Pad. 20 Mostra d'Oltremare, 80125 Naples, Italy.
}

Andrea Salvo, asalvo@unime.it

Archimede Rotondo, arotondo@unime.it

Valentina Mangano, vmangano@unime.it

Manuela Grimaldi, magrimaldi@unisa.it

Ilaria Stillitano, istillitano@unisa.it

Anna Maria D’Ursi, dursi@unisa.it

Giacomo Dugo, dugog@unime.it

Luca Rastrelli, rastrelli@unisa.it

*Address correspondence to Archimede Rotondo Dep. Biomorf., University of Messina, Italy; Phone: +390906766890;

E-mail: arotondo@unime.it 
Almonds are the tasty seeds of Prunus dulcis plants globally appreciated for the pleasant palatability and remarkable nutritional value, therefore it is very spread as snack and as basic ingredient of the confectionery products. The HR-MAS-NMR is a simple spectroscopy able to directly and quickly explore the chemical composition of powdered seed samples dispersed in $\mathrm{D}_{2} \mathrm{O}$. ${ }^{1} \mathrm{H}$ spectra witness the remarkable presence of triglyceride fatty esters together with sucrose; other minor water soluble metabolites are also detectable. This very rough approach is effectively providing chemical profiles featuring almond samples. In this analysis we were able to statistically distinguish the "Avola" almonds from other marketed products submitted to the same analysis. This is just a first investigation based on the main compounds but it might pave the way toward the quantitative evaluation of many other compounds in the almond therefore implementing the HRMAS-NMR knowledge of these precious seeds.

Keywords: Food composition, HR-MAS-NMR, almonds, PCA, Quantification.

\section{Extended Introduction}

Almonds (Prunus Dulcis) belong to the Rosaceae family and are globally appreciated for their sensory and health features; as it is an important element of the Mediterranean diet and main ingredient of many confectionery industries, almond trees are the most grown on a global basis (Wijeratne et al. 2006; Chen et al. 2005). Many Mediterranean regions are characterized by these plants bearing a considerable commercial value (Cordeiro and Monteiro 2001; Martins et al. 2003; Cicero et al. 2015; Albergamo et al. 2017; Costa et al. 2018). The edible fruit presents three distinct parts: 1) the inner kernel or meat (sold with or without the brown skin), 2) the middle shell portion, and an outer green shell cover or hull. All these parts are deeply studied for the chemical composition being the meat the most important consumable food whereas the outer parts can be recycled as "useful waste" (Esfahlan et al. 2010). Almonds are a rich source of essential fatty acids, carbohydrate and protein and is a highly nutritional source of vitamins, minerals (Gallier et al. 2012; Shi Z et al. 1999) and antioxidant species claimed to slow aging processes (Franklin et al. 2017). This accounts for the careful chemical analyses of almonds aimed to elucidate the beneficial effects of derived products upon the human health (Zeeshan 2010; Geng et al. 2016). 
Almonds, when incorporated in the diet, have been reported to reduce colon cancer risk in rats (Davis and Iwahashi 2001) and increase the "good cholesterol" (high density lipo-proteins, HDL) in spite of the "bad cholesterol" (low density lipo-proteins, LDL) levels in humans (Hyson et al. 2002). Extracts of whole almond seed, brown skin, shell, and green shell cover (hull) possess potent free radical-scavenging capacities (Amarowicz et al. 2005; Sfahlan et al. 2009; Moure et al. 2007; Pinelo et al. 2004; Siriwardhana Wijeratne et al. 2006; Siriwardhana Wijeratne and Shahidi 2002; Wijeratne et al. 2006). These activities may be related to the presence of flavonoids and other phenolic compounds. Almond hulls have been shown to serve as a rich source of three triterpenoids (about 1\% of the hulls), betulinic, urosolic and oleanolic acids (Takeoka et al. 2000), as well as flavonol glycosides and phenolic acids (Sang et al. 2002; Shahidi et al. 2009). In addition, Sang, Chen et al. (2002), Sang, Lapsley et al. (2002), and Sang, Lapsley, Rosen et al. (2002) isolated catechin, protocatechuic acid, vanillic acid, p-hydroxybenzoic acid, and naringenin glucoside, as well as galactoside, glucoside, rhamnoglucoside of 3 $\beta$-O-methylquercetin and rhamnoglucoside of kaempferol. In the field of the chemical studies, nuclear magnetic resonance (NMR) is an irreplaceable tool for the chemical characterization (Rotondo et al. 2012; Rotondo et al. 2014a), elucidation of structures and molecular dynamic behaviour (Rotondo et al 2014b; Rotondo et al 2015), allowing also characterization of complex mixtures (Salvo et al. 2017). NMR spectroscopy is very efficient for the simultaneous detection and identification of several metabolites (Rotondo et al. 2011, Rotondo et al. 2018) indeed almond oils were deeply analyzed by high resolution NMR (Popescu et al. 2015; Vigli et al. 2003) as well as the almonds water-soluble extracts (Tanaka et al. 2013).

HR-MAS NMR spectroscopy opened-up the chance to analyse the solid and semisolid matter (Corsaro et al. 2016) which, in the case of the Prunus Dulcis turned out to allow direct chemical changes undergone by almonds upon irradiation processes (Ribó et al. 2004), the aim of this work was to characterize the chemical composition of Prunus Dulcis by HR-MAS NMR providing the symultaneous relative quantification of very different chemical species as fats and carbohydrates. According to us this is the first NMR HR-MAS specifically aimed to draw chemical profiles related to different kind of marketed edible Prunus Dulcis seeds, paving the way to deeper investigations on this interesting matrix. 


\section{Immages}

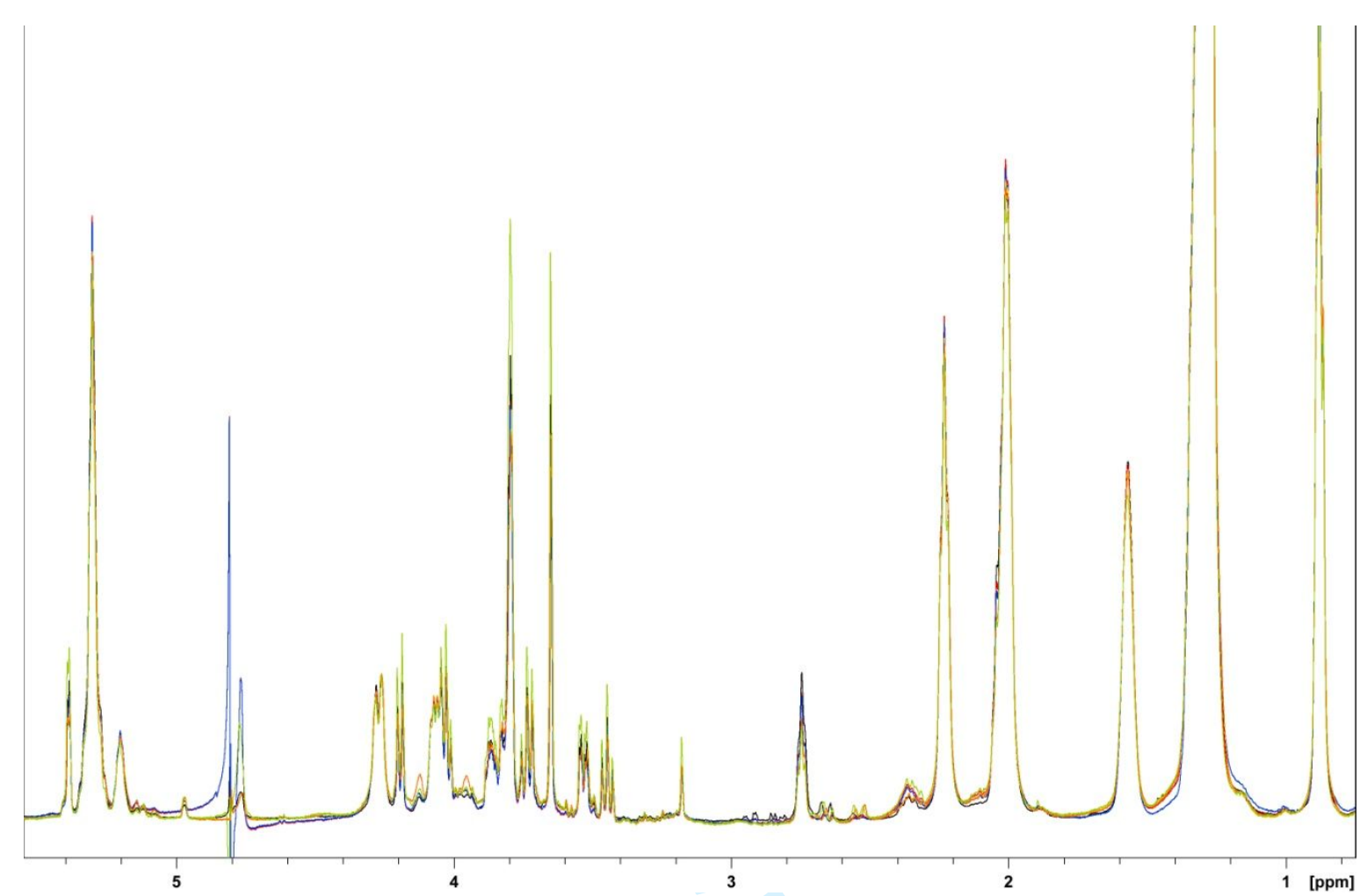

Figure 1S. HR-MAS 1H-NMR traces of the 24 analysed samples showing a pretty centred alignment and allowing the serial integration for the quantification

Table 1S. Specification of the provenience and packaging for the 24 analysed samples.

\begin{tabular}{|c|c|c|c|}
\hline Samples & Declared Geographical Origin & Labels & Lots \\
\hline S_1_1 & \multirow{8}{*}{ California } & \multirow{5}{*}{ package 1 marketed in Europe } & 1 \\
\hline S_1_2 & & & 2 \\
\hline S_1_3 & & & 3 \\
\hline S_1_4 & & & 4 \\
\hline S_1_5 & & & 5 \\
\hline S_2_1 & & \multirow{3}{*}{ package 2 marketed in Europe } & 1 \\
\hline S_2_2 & & & 2 \\
\hline S_2_3 & & & 3 \\
\hline
\end{tabular}




\begin{tabular}{|c|c|c|c|}
\hline S_3_1 & & \multirow{3}{*}{ package 3 Marketed in Europe } & 1 \\
\hline S_3_2 & & & 2 \\
\hline S_3_3 & & & 3 \\
\hline S_4_1 & & \multirow{3}{*}{ package 4 marketed in Italy } & 1 \\
\hline S_4_2 & & & 2 \\
\hline S_4_3 & & & 3 \\
\hline S_5_1 & & \multirow{3}{*}{ package 5 marketed in Italy } & 1 \\
\hline S_5_2 & Italy & & 2 \\
\hline S_5_3 & & & 3 \\
\hline S_6_1 & & \multirow{3}{*}{ package 6 marketed in Italy } & 1 \\
\hline S_6_2 & & & 2 \\
\hline S_6_3 & & & 3 \\
\hline S_7_1 & \multirow{3}{*}{$\begin{array}{l}\text { Avola Almonds from sicilian } \\
\text { cultivars }\end{array}$} & \multirow{3}{*}{$\begin{array}{l}\text { Almods directly collected from the } \\
\text { farm (Siracusa, Sicily) }\end{array}$} & land 1 \\
\hline S_7_2 & & & land 2 \\
\hline S_7_3 & & & land 3 \\
\hline
\end{tabular}

Table 2S. Extended table of the relative quantification (molecolar \% respect to the total tiacylglycerols) for several almond metabolites.

\begin{tabular}{|c|c|c|c|c|c|c|c|c|}
\hline Sample & $\begin{array}{c}\text { Saturated } \\
\text { fatty esters } \\
\%\end{array}$ & $\begin{array}{c}\text { Oleate } \\
\text { fatty } \\
\text { esters \% }\end{array}$ & $\begin{array}{c}\text { Linoleate } \\
\text { fatty esters } \\
\%\end{array}$ & $\begin{array}{c}\text { Sucrose } \\
\text { relative } \\
\%\end{array}$ & $\begin{array}{c}\text { Asparagine } \\
\%\end{array}$ & $\begin{array}{c}\text { Proline } \\
\%\end{array}$ & $\begin{array}{c}\text { Malate } \\
\%\end{array}$ & $\begin{array}{c}\text { phospho- } \\
\text { choline } \\
\text { derivates } \\
\%\end{array}$ \\
\hline code & SAT & O & L & SUC & ASN & PRO & MAL & PCHO \\
\hline S_1_1 & 11.3 & 61.5 & 27.2 & 79.8 & 36.0 & 4.8 & 24.2 & 1.6 \\
\hline S_1_2 & 12.9 & 59.3 & 27.9 & 77.9 & 37.5 & 4.9 & 25.7 & 1.5 \\
\hline S_1_3 & 12.4 & 60.1 & 27.5 & 76.2 & 35.4 & 5.0 & 23.4 & 1.6 \\
\hline
\end{tabular}




\begin{tabular}{|c|c|c|c|c|c|c|c|c|}
\hline S_1_4 & 11.8 & 60.9 & 27.3 & 78.3 & 33.7 & 5.0 & 23.3 & 1.5 \\
\hline S_1_5 & 11.3 & 61.5 & 27.2 & 79.8 & 36.0 & 5.0 & 24.1 & 1.6 \\
\hline S_2_1 & 9.2 & 68.9 & 21.9 & 70.7 & 14.3 & 5.0 & 31.9 & 1.5 \\
\hline S_2_2 & 9.9 & 67.7 & 22.4 & 73.5 & 15.8 & 5.0 & 34.9 & 1.5 \\
\hline S_2_3 & 10.1 & 67.5 & 22.5 & 72.8 & 15.8 & 4.9 & 34.3 & 1.5 \\
\hline S_3_1 & 9.3 & 69.7 & 21.0 & 77.1 & 12.3 & 5.0 & 29.7 & 1.6 \\
\hline S_3_2 & 9.1 & 69.5 & 21.4 & 68.7 & 12.3 & 5.0 & 29.7 & 1.6 \\
\hline S_3_3 & 9.1 & 68.9 & 22.0 & 72.5 & 16.8 & 5.0 & 35.2 & 1.4 \\
\hline S_4_1 & 12.5 & 69.3 & 18.2 & 70.1 & 1.2 & 4.8 & 23.3 & 1.6 \\
\hline S_4_2 & 11.8 & 70.2 & 17.9 & 71.8 & 0.9 & 4.5 & 23.6 & 1.6 \\
\hline S_4_3 & 10.8 & 71.6 & 17.6 & 72.9 & 0.0 & 3.5 & 21.7 & 1.6 \\
\hline S_5_1 & 12.6 & 69.1 & 18.3 & 70.6 & 0.8 & 3.7 & 22.6 & 1.6 \\
\hline S_5_2 & 10.5 & 72.1 & 17.4 & 73.9 & 1.8 & 4.7 & 24.1 & 1.6 \\
\hline S_5_3 & 11.9 & 69.9 & 18.2 & 70.8 & 0.9 & 4.4 & 22.7 & 1.7 \\
\hline S_6_1 & 12.0 & 69.9 & 18.0 & 71.4 & 1.0 & 4.6 & 24.0 & 1.6 \\
\hline S_6_2 & 14.1 & 66.6 & 19.3 & 70.3 & 3.5 & 4.5 & 26.1 & 1.5 \\
\hline S_6_3 & 11.6 & 67.5 & 20.9 & 78.2 & 47.0 & 5.0 & 46.4 & 2.6 \\
\hline S_7_1 & 12.7 & 69.6 & 17.7 & 106.8 & 17.6 & 5.0 & 46.5 & 2.8 \\
\hline S_7_2 & 10.2 & 73.3 & 16.4 & 113.7 & 15.5 & 5.0 & 46.7 & 2.9 \\
\hline S_7_3 & 11.0 & 72.2 & 16.8 & 111.0 & 16.1 & 5.0 & 46.2 & 2.9 \\
\hline
\end{tabular}

PCA Analysis 


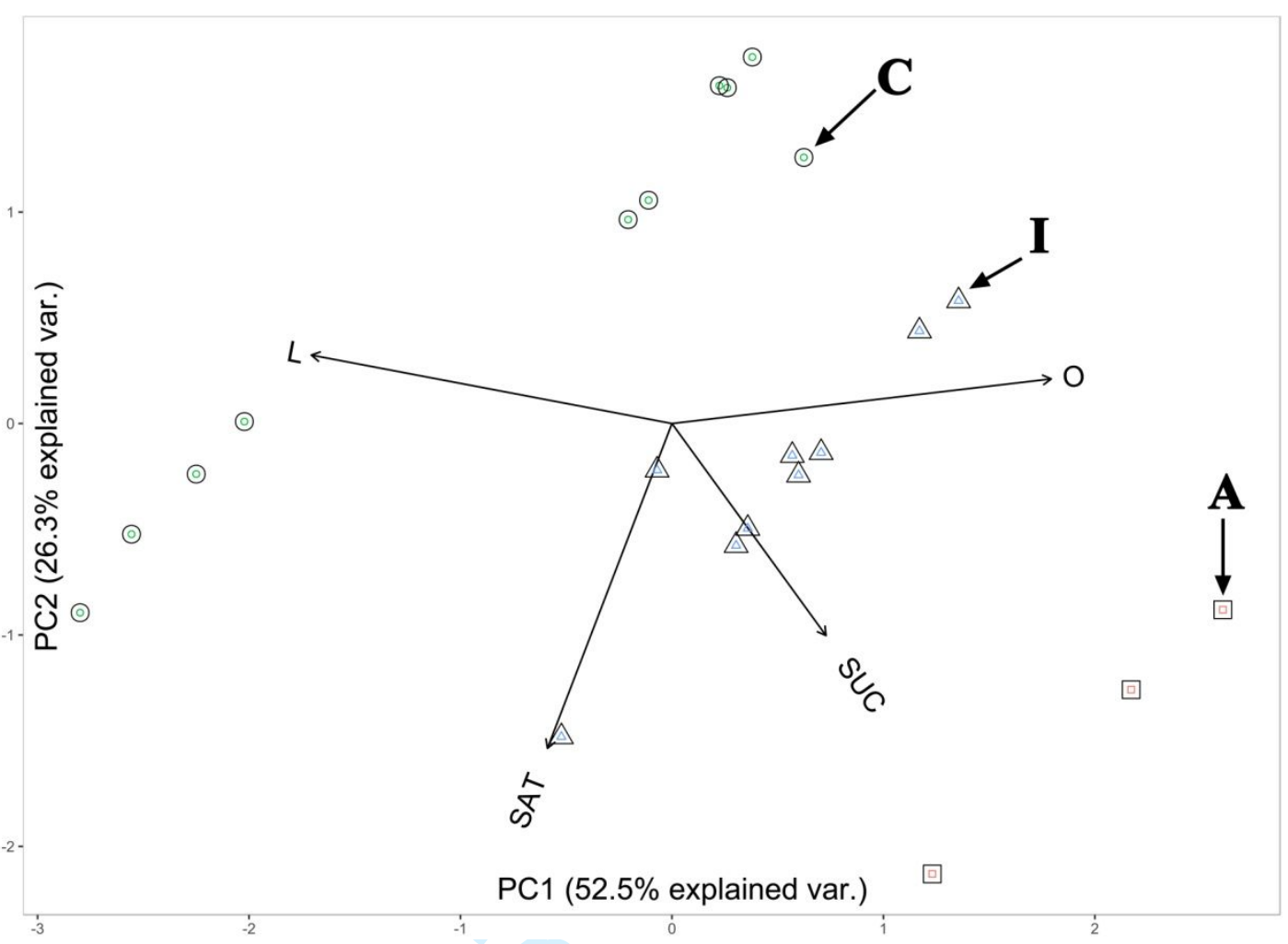

Figure 2S. Principal component analysis for the 24 NMR analysed samples referred to the four most represented quantitative values: the plot separates without any supervision the different declared origin ( $\mathrm{C}=$ Californian, $\mathrm{I}=$ Italian, $\mathrm{A}=$ "Avola" species directly collected from the trees).

\section{Extended related references:}

Ahmad Z. 2010. The uses and properties of almond oil. Complementary Therapies in Clinical Practice 16:10-12

Albergamo A, Rotondo A, Salvo A, Pellizzeri V, Bua DG, Maggio A, Cicero N, Dugo G. 2017.

Metabolite and mineral profiling of "Violetto di Niscemi" and "Spinoso di Menfi" globe artichokes by1H-NMR and ICP-MS. Natural Product Research, 31 (9):990-999.

Barreira JCM, Casal S, Ferreira ICFR, Peres AM, Pereira JA, Oliveira MBPP. 2012. Supervised Chemical Pattern Recognition in Almond (Prunus dulcis) Portuguese PDO Cultivars: PCA- and LDA-Based Triennial Study. J. Agric. Food Chem., 60:9697-9704 
Chen CY, Milbury PE, Lapsley K, Blumberg JB. 2005. Flavonoids from almond skins are bioavailable and act synergistically with vitamins $\mathrm{C}$ and $\mathrm{E}$ to enhance hamster and human LDL resistance to oxidation. Journal of Nutrition. 135:1366-1373.

Cicero N, Corsaro C, Salvo A, Vasi S, Giofrè SV, Ferrantelli V, Di Stefano V, Mallamace D, Dugo G. 2015. The metabolic profile of lemon juice by proton HR-MAS NMR: The case of the PGI Interdonato Lemon of Messina. Natural Product Research, 29 (20):1894-1902.

Cordeiro V, Monteiro A. 2001. Almond growing in Tras-os-Montes region (Portugal). Acta Horticulture. 591:161-165.

Corsaro C, Cicero N, Mallamace D, Vasi S, Naccari C, Salvo A, Giofrè SV, Dugo G. 2016. HRMAS and NMR towards Foodomics. Food Research International, 89: 1085-1094.

Costa R, Salvo A, Rotondo A, Bartolomeo G, Pellizzeri V, Saija E, Arrigo S, Interdonato M, Trozzi A, Dugo G. 2018. Combination of separation and spectroscopic analytical techniques: application to compositional analysis of a minor citrus species. Natural Product Research, 32 (21): 2596-2602.

Davis PA, Iwahashi CK. 2001. Whole almonds and almond fractions reduce aberrant crypt foci in a rat model of colon carcinogenesis. Cancer Letters. 165:27-33.

Esfahlan AJ, Jamei R, Esfahlan RJ. 2010. The importance of almond (Prunus amygdalus L.) and its by-products. Food Chemistry. 120:349-360.

Franklin LM, Chapman DM, King ES, Mau M, Huang G, Mitchell AE. 2017. Chemical and Sensory Characterization of Oxidative Changes in Roasted Almonds Undergoing Accelerated Shelf-life. Journal of Agricultural and Food Chemistry. 65:2549-2563.

Gallier S, Gordon KC, Singh H. 2012. Chemical and structural characterisation of almond oil bodies and bovine milk fat globules. Food Chemistry. 132:1996-2006.

Geng H, Yu X, Lu A, Cao H, Zhou B, Zhou L, Zhao Z. 2016. Extraction, Chemical Composition, and Antifungal Activity of Essential Oil of Bitter Almond. International Journal of Molecular Sciences. 17:1421. 
Hyson DA, Schneeman BO, Davis PA. 2002. Almonds and Almond Oil Have Similar Effects on Plasma Lipids and LDL Oxidation in Healthy Men and Women. The Journal of Nutrition. 132: $703-707$.

Martins M, Tenreiro R, Oliveira MM. 2003. Genetic relatedness of Portuguese almond cultivars assessed by RAPD and ISSR markers. Plant Cell Reports. 22:71-78.

Moure A, Pazos M, Medina I, Domínguez H, Parajó JC. 2007. Antioxidant activity of extracts produced by solvent extraction of almond shells acid hydrolysates. Food Chemistry. 101:193-201.

Pinelo M, Rubilar M, Sineiro J, Núñez MJ. 2004. Extraction of antioxidant phenolics from almond hulls (Prunus amygdalus) and pine sawdust (Pinus pinaster). Food Chemistry. 85:267-273.

Popescu R, Costinel D, Dinca OR, Marinescu A, Stefanescu I, Ionete RE. 2015. Discrimination of vegetable oils using NMR spectroscopy and chemometrics. Food Control. 48: 84-90.

Ribó JM, Crusats J, El-Hachemi Z, Feliz M, Sanchez-Bel P, Romojaro F. 2004. High-Resolution NMR of Irradiated Almonds. Journal of the American Oil Chemists' Society. 81(11): 1029-1033.

Rotondo A., Barresi S., Cusumano M., Rotondo E. 2012. Structural and dynamic NMR characterization of $\left[\mathrm{Pd}(\text { bipy })(\mathrm{R} \text {-thiourea })_{2}\right]^{2+}$ and $\left[\mathrm{Pd}(\mathrm{phen})(\mathrm{R} \text {-thiourea })_{2}\right]^{2+}$ cations. Polyhedron 45(1):23-29

Rotondo A., Barresi S., Cusumano M., Rotondo E., Donato P., Mondello L. 2014a. NMR characterisation and dynamic behaviour of $\left[\mathrm{Pt}(\right.$ bipy $\left.)(\mathrm{R}-\mathrm{Thiourea})_{2}\right] \mathrm{Cl}_{2}$ and $[\mathrm{Pt}(\mathrm{phen})(\mathrm{R}-$ Thiourea $\left.)_{2}\right] \mathrm{Cl}_{2}$ complexes. Inorganica Chimica Acta 410:1-10

Rotondo A., Ettari R., Zappalà M., De Micheli C., Rotondo E. 2014b. NMR characterization and conformational analysis of a potent papain-family cathepsin L-like cysteine protease inhibitor with different behaviour in polar and apolar media Journal of Molecular Structure, 1076:337-343.

Rotondo A., Ettari R., Grasso S., Zappalà M. 2015. NMR conformational analysis in solution of a potent class of cysteine proteases inhibitors Structural Chemistry 26(4): 943-950 
Rotondo A, Salvo A, Gallo V, Rastelli L, Dugo G. 2017. Quick unreferenced NMR quantification of Squalene in vegetable oils. European Journal of Lipid Science and Technology. 119(11). Article number 1700151.

Rotondo A, Salvo A, Giuffrida D, Dugo G, Rotondo E. 2011. NMR analysis of aldehydes in sicilian extra-virgin olive oils by DPFGSE techniques. AAPP Atti della Accademia Peloritana dei Pericolanti, Classe di Scienze Fisiche, Matematiche e Naturali. 89(1). DOI: 10.1478/C1A8901002

Salvo A, Rotondo A, La Torre GL, Cicero N, Dugo G. 2017. Determination of 1,2/1,3-diglycerides in Sicilian extra-virgin olive oils by ${ }^{1} \mathrm{H}-\mathrm{NMR}$ over a one-year storage period. Natural Product Research. 31(7):822-828.

Sang S, Cheng X, Yin FH, Shieh DE, Bai N, Lapsley K, Stark RE, Rosena RT, Hoa CT. 2002. New type sesquiterpene lactone from almond hulls (Prunus amygdalus Batsch). Tetrahedron Letters. 43:2547-2549.

Sang S, Lapsley K, Jeong WS, Lachance PA, Ho CT, Rosen RT. 2002. Antioxidative Phenolic Compounds Isolated from Almond Skins (Prunus amygdalus Batsch). Journal of Agriculture and Food Chemistry. 50: 2459-2463.

Sang S, Lapsley K, Rosen RT, Ho CT. 2002. New prenylated benzoic acid and other constituents from almond hulls (Prunus amygdalus Batsch). Journal of Agriculture and Food Chemistry. 50: 607-609.

Sfahlan AJ, Mahmoodzadeh A, Hasanzadeh A, Heidari R, Jamei R. 2009. Antioxidants and antiradicals in almond hull and shell (Amygdalus communis L.) as a function of genotype. Food Chemistry. 115:529-533.

Shahidi F, Zhong Y, Wijeratne SSK, Ho CT. 2009. Almond and almond products: Nutraceutical components and health effects. Tree nuts: nutraceuticals, phytochemicals, and health effects, Taylor \& Francis Group. 8:127-141. 
Siriwardhana Wijeratne SSK, Amarowicz R, Shahidi F. 2006. Antioxidant Activity of Almonds and Their By-products in Food Model Systems. Journal of the American Oil Chemists' Society. 83:223230.

Siriwardhana Wijeratne SSK, Shahidi F. 2002. Antiradical activity of extracts of almond and its byproducts. Journal of the American Oil Chemists' Society. 79(9): 903-908.

Takeoka G, Dao L, Teranishi R, Wong R, Flessa S, Harden L, Edwards R. 2000. Identification of three triterpenoids in almond hulls. Journal of Agriculture and Food Chemistry. 48: 3437--3439.

Tanaka R, Nitta A, Nagatsu A. 2013. Application of a quantitative ${ }^{1} \mathrm{H}-\mathrm{NMR}$ method for the determination of amygdalin in Persicae semen, Armeniacae semen, and Mume fructus. Journal of Natural Medicines. 68(1):225-230.

Vigli G, Philippidis A, Spyros A, Dais P. 2003. Classification of Edible Oils by Employing ${ }^{31} \mathrm{P}$ and ${ }^{1} \mathrm{H}$ NMR Spectroscopy in Combination with Multivariate Statistical Analysis. A Proposal for the Detection of Seed Oil Adulteration in Virgin Olive Oils. Journal of Agriculture and Food Chemistry. 51:5715-5722.

Wijeratne SSK., Abou-zaid MM, Shahidi F. 2006. Antioxidant polyphenols in almond and its coproducts. Journal of Agriculture and Food Chemistry. 54:312-318.

Zeeshan, A. 2010. The uses and properties of almond oil. Complementary Therapies in Clinical Practice. 16:10-12. 